\title{
EL TRABAJO MINERO: DERECHO Y LENGUAJE A TRAVÉS DE LOS SIGLOS
}

\author{
José Antonio González Pizarro \\ Escuela de Derecho \\ Universidad Católica del Norte \\ Antofagasta
}

En Hispanoamérica se asistió durante los tiempos coloniales y primeros de la era republicana a una conexión armoniosa entre la designación del trabajo, la descripción de la faena y la acogida de todo esto en la regulación jurídica epocal que la afectaba. Esto delataba una comunicación entre el uso lingüístico del español y el de las lenguas vernáculas del continente, principalmente el de las altas culturas indígenas, sobresaliendo la incaica, en lo que nos interesa apuntar en relación a las actividades mineras $^{127}$.

Lo aseverado, al ser heredado por las nacientes repúblicas, no sólo como estructuras económicas sociales sino también por los mismos ordenamientos legales, se mantuvo durante gran parte del siglo XIX. Pero, también se pudo presenciar cómo determinadas costumbres e ideas en torno a algunas formas de higiene en los campamentos mineros, que trasuntaban modos inveterados de mentalidades anteriores al siglo XIX, pudieron ser modificadas por reglamentaciones propias de las Compañías mineras extranjeras, principalmente de capitales anglosajones ${ }^{128}$.

Este conjunto de observaciones nos pone en la evidencia de la relación recíproca entre el Derecho y la Sociedad. Esta última impactando con el lenguaje vital-aquél de lo hablado en los estratos vinculados con la actividad minera-al vocabulario jurídico concerniente con la conceptualización y descripción de las faenas y operarios. Pero

${ }^{127}$ Hasta la promulgación de la Cédula de Aranjuez del 10 de mayo de 1770 , en que se estableció el español como lengua única en el continente americano, la riqueza de las lenguas indígenas, desde las primeras voces taínas-como el "guanín"-pasando por los nahuatlismos, quechuas, etc. hubo preocupación por conformar diccionarios de español y lenguas indígenas. Véase, Angel Rosenblat, "La hispanización de América.El castellano y las lenguas indigenas desde 1492". En Presente y futuro de la lengua española, Madrid, 1964. llustrativo es lo ocurrido con la voz "yanacona" que, al decir de un historiador del derecho peruano, "tiene múltiples interpretaciones en cuanto a su raíz etimológica y ha sufrido una orientación conceptual en los sistemas pre indiano, indiano y republicano", Cf. Jorge Basadre Ayulo, "Algunas consideraciones sobre el yanaconaje en la legislación indiana peruana", en IX Congreso del Instituto Internacional de Historia del Derecho Indiano. Actas y Estudios, Madrid, 1991. Tomo II, 58 .

El vocablo "rancho", proveniente también de las Antillas, tuvo mejor fortuna y acompañó las disposiciones laborales coloniales, como puede observarse en Alvaro Jara-Sonia Pinto, Fuentes para la historia del trabajo en el Reino de Chile. Legislación, 15461810, Editorial A. Bello, 1982, Tomo I.

${ }^{128}$ Para la formación de los campamentos mineros -"company- towns"-, como propios de las iniciativas privadas en las nuevas fronteras económicas, J.D. Porteous ha explicado su generación en el ámbito cuprero, Cf. "Social Class in Atacama Company Towns", Annals of the Association of American Geographers, 1974, 64-3, pp. 409-417.

El cambio en las mentalidades del peón minero en el caso de Chuquicamata, se constata en lo aseverado por lo periódicos regionales La Industria, Calama, 24, 29 y 31 de marzo de 1918, y por La Semana, Antofagasta, 7,14 de abril y 12 y 26 de mayo de 1918. 
también lo jurídico mudando, con el rasgo de la coacción, lo apreciado en la cotidaneidad de la vida laboral.

Desde el siglo XVI se empezó a estructurar en América el ordenamiento jurídico de las Minas. Se debió a Francisco Toledo, cuya administración al frente del Virreinato del Perú comienza en 1569, la principal reglamentación minera, conocida como Ordenanzas de Toledo, de $1574^{129}$

En su obra legislativa quedó incorporado todo el mundo incaico en cuanto a las labores mineras: yanaconazgos, mitas, trabajo en las minas de plata y de azogue, impuestos, etc.

Destaquemos que la publicación y circulación de libros en la América Colonial estaba demarcada por distintas disposiciones legales que, posteriormente, fueron recepcionadas en la Recopilación de las Leyes de Indias de 1680, en cuyo Libro I, Título $X X I V$, Ley III, refiere que, cuando se hiciere algún Arte, ó Vocabulario de la lengua de los Indios, no se publique, ni se imprima, ni use de él, si no estuviere primero examinado por el Ordinario, y visto por la Real Audiencia del distrito" ${ }^{130}$.

La propia legislación indiana se sirvió entonces de giros lingüísticos aborígenes para aludir a determinadas formas de trabajos mineros. Vocablos antillanos sirvieron para designar el trabajo y calidad de determinados metales. Por ejemplo, del laboreo aurífero,una disposición del rey Carlos I, de 1519, refiere del oro en poder de los indígenas "que antiguamente solían llamar guanín, y es oro muy baxo"131 .

La mita constituyó la incorporación léxica más notable procedente de un idioma natural a la lengua castellana, reuniendo en su concepto la antigua institución minera incaica que apuntaba al trabajo por turnos, de diez meses para cada año. Los indígenas que debían concurrir fueron denominados mitayos. En torno a la mita emergieron distintos tipos de mineros: los barreteros, "que son los que quiebran el metal", los apires, "que son los que lo sacan de lo interior de la mina, fuera de ella", los describía Pedro Vicente Cañete y Domínguez en su obra Guía histórica, geográfica, física, política, civil y legal del gobierno e intendencia de la provincia de Potosí, de $1787^{132}$. Estos eran los indios mingados, a los que se les alquilaba sus servicios.

La mita peruana se conoció en México como cuatequil y ambas sirvieron para denominar inequívocamente una forma de trabajo, tanto en las haciendas como en las minas.

${ }^{129}$ Vid. Alejandro Vergara Blanco, Principios y sistema del Derecho Minero. Estudio Histórica-Dogmático, Santiago de Chile, 1992.

${ }^{130}$ Recopilación de Leyes de los Reynos de las Indias, Madrid, MDCCLXXXI, Quarta Impresión, Tomo II, 213-214.

${ }^{131}$ Recopilación de Leyes, op.cit.. Tomo II, p. 75.

El vocablo "guanín" provenía de los naturales de Antillas y aludía al oro de baja ley o bien a la joya fabricada en oro por los indios. La palabra "guanín" todavia está vigente, según el Diccionario de la Real Academia Española, Madrid, 1984, vigésima edición, tomo II, 706.

${ }^{132}$ Pedro Vicente Cañete y Dominguez, Guía histórica, geográfica, fisica, política, civil y legal del gobierno e intendencia de la provincia de Potosi (1787), Potosí, 1952, p.1112. Registremos que la ardua tarea de la Mita asoció a ella la voz chasquear, o sea, "destrozar a golpe de piedra u otro instrumento". Cf. José Antonio González Pizarro, "La mita y los mitayos en el Potosí finisecular del siglo XVIII. El parecer del jurista Pedro Vicente Cañete y Domínguez", Revista de Derecho de Minas. Universidad de Atacama, año 1993, Vol. IV, 34. 
Hacia fines del siglo XVIII cuando, la introducción de nuevas tecnologías para el laboreo y ensaye de los metales, junto con una mayor preocupación por el tecnicismo jurídico, en una atmósfera de creciente ánimo reformista ilustrado estimulado por la Monarquía borbónica,se modifique el marco jurídico prevaleciente, por las Reales Ordenanzas del Cuerpo de Minería de Nueva España de 1783, se observará una mayor incorporación de las voces castellanas en vez de las aborígenes en el ámbito minero. Sin embargo, se puede advertir ligeramente que el uso del castellano tendió a describir en el texto jurídico la faena, los operarios, cuando el vocablo indígena, dado el empleo consuetudinario, no requería descripción alguna.

Este cambio jurídico significó hacer la distinción artificial entre lo que comúnmente se conocía como "mineros", barreteros o apires, también reconocidos como peones, por el de "operarios o sirvientes de minas", lo cual hizo que dependiera del arraigo de la costumbre lingüística en el seno de la sociedad dieciochesca el éxito o fracaso de la artificialidad designativa de las Ordenanzas de 1783. Minero, establecía la Ordenanza,aludía al propietario o dueño de mina, pero también al "perito intelijente" que llamará "guardamina", como era común conocer en Nueva España, según reconocía en su Título I. Artículo 3; Título 9, Artículo 2, respectivamente. De igual modo,se apartaba de lo que se llamaba vulgarmente "mina". Refiere el corpus legal de amarras, en la "Introducción" al Título VI: "Aunque comúnmente se llaman minas los depósitos de sustancias útiles a la industria, $\mathrm{i}$ en este sentido se dice se ha descubierto, se ha pedido una mina, mas propiamente se da este nombre al conjunto de trabajos ejecutados con el objeto de estraer de la tierra productos minerales útiles a la industria. En este sentido, la palabra mina comprende dos ideas: el trabajo i los minerales útiles a la industria".

La superación de algunas designaciones populares e empleadas en el ámbito jurídico supuso una mayor precisión técnica y la adición de nuevas palabras. Haciéndose la distinción de minerales metálicos y no metálicos, se avanzó hacia cómo se encontraban estos productos en la naturaleza. De esta manera se discriminó entre depósitos regulares o irregulares. Los primeros conformando capas o mantos, vetas y filones. De esta clasificación, hacía notar que "formando lo que en el lenguaje vulgar se llama lavadero i en el de la Ordenanzas placeres, se encuentrarı también en capas de oro, el platino".

Volviendo al conocimiento popular consignaba que al cerro, con relación a las vetas " se le llamaba roca, panizo, piedra bruta i aun criadero"133.

En cuanto a los segundos, precisaba que podían ser rebosaderos o en masas.

Otras palabras que mantuvieron su sentido fueron "cata", "a tajo abierto". "estacadas", aunque quedaba la discusión sobre qué debía entenderse en propiedad por "estaca fija". Antiguamente era respecto a la pertenencia de la principal boca o labor de la mina.

Otros vocablos fueron difundidos como "terrenos", los lugares donde se arrojan las tierras, tepetates i desmontes; donde el "tepetate" es la tierra de mina que no tiene metal, y el "desmontes" las piedras estériles o sin suficiente ley que se botan porque no se puede beneficiarlas, etc.

${ }^{133}$ José Bernardo Lira, Esposición de las Leyes de Minería de Chile, Valparaíso, Imp.del Mercurio, 1870, 64-85 
Al lado de éstas se incorporaron las precisiones relacionadas con la geomensura: "afloramiento" o "corrida", "dirección" o "rumbo", "inclinación", "echado" o "recuesto", "manteo", "cuadra", etc.

No obstante, determinadas locuciones se mantuvieron para referirse a situaciones conexas con el aprovechamiento de las minas. El Título VIII de las Ordenanzas en comento refiere textualmente: "con veta en la mano", "en seguimiento del metal que lleva", para aludir, en la primera locución, a las labores emprendidas o continuadas en broceo, sin beneficio actual, y en la segunda, al minero que va siguiendo buenamente sus labores, sin la intención de alcanzar la pertenencia ajena. Las contrarias, con el propósito de tomar el mineral de otra se les conocía como "bocas ladronas".

Cuando una veta descubría a gran profundidad su principal riqueza o desaparecía en algunos trechos para reaparecer más adelante se le denominaba de dos formas. Para Francisco Xavier Gamboa,en su obra Comentarios a las Ordenanzas de Minas, ${ }^{134}$, que atendía a las Ordenanzas del Nuevo Cuaderno, de 1584, era "emborrascarse" la veta; en Perú se hablaba de "chingarse" para aludir al hecho de la desaparición de una veta, según consignaba José Rossi y Rubí, en su Diccionario de algunas voces técnicas de Mineralogía y metalurgia municipales en las Provincias de este Reyno del Perú, indicadas por orden alfabético y compilada por los Autores del mismo Mercurio, de $1791 .^{135}$ brinco".

Para los mineros chilenos de la primera mitad del siglo XIX era "brincar" o "dar

Otras voces serán asumidas por la costumbre criolla y por nuestra literatura minera. Las labores mineras practicadas en el interior de los cerros, tomaban el nombre de "piques" cuando eran verticales o cuando formaban con la vertical-comentaba el especialista José Bernardo Lira-un ángulo de menos de $45^{\circ}$. Entonces se llamaban piques "inclinados", "achiflonados" o bien "chiflón". Esto último conocido en las minas de carbón y proyectado literariamente por Baldomero Lillo, en su cuento "El Chiflón del Diablo". 136

De algunos contratos surgieron prototipos sociales que se conocerán en todos los rincones, como los "aviadores", que derivaba del avio, o sea, del dinero o efectos que se entregaba a alguien para el fomento de minas. En otros casos, de la observancia de algunos hechos, como la venta y compra de metales en determinadas regiones, pesó más que la regulación artificial. Así, las citadas Ordenanzas incorporaban a los "maquileros": "Las costumbres observadas en Nueva España (México) de ser lícito i libre a cualquiera el comprar i vender metales en piedra y establecer oficinas en que beneficiarlos aunque no tengan minas los que las construyan, es mi soberana voluntad $i$ mando que seconserven i fomenten ambas costumbres"(Título XIV, Art.1).

Los "maquileros" eran los molineros que reducían los minerales en metales. Derivaba el nombre de los molinos usados, con lo cual ponía el acento de la continuidad

${ }^{134}$ Vid. Francisco Xavier de Gamboa, Comentarios a las Ordenanzas de Minas, dedicados al Catholico Rey, Nuestro Señor, Don Carlos III... Con aprobación y privilegio del rey, Madrid, 1761.

${ }^{135}$ Cf. Antonio Dougnac Rodríguez, "Derecho Minero Indiano: voces técnicas peruanas del siglo XVIII", Revista de Derecho de Minas y Aguas, Vol.II, 1991, 29.

${ }^{136}$ Baldomero Lillo, "El chiflón del diablo" in Subterra, Edit. A. Bello, 1983. 
de un vocablo de procedencia árabe que asentado en la cultura hispánica traspasó el Atlántico para definir una labor en América.

El "apiri" se consigna en el Diccionario de Rossi y Rubí como "el operario que carga el metal o desmonte extraído de la Mina, en sacos de cuero, que se llaman Capachos". ${ }^{137}$

Este "apir" es el que se desenvuelve en el periodo republicano, siendo observado por Darwin en 1834 y por José Joaquín Vallejos-Jotabeche-en 1842. De este sustantivo, acota Mario Bahamonde, surgió el verbo "apirear". ${ }^{138}$

Desde tiempos coloniales se empezaron a conocer los "pirquineros" como aquellos mineros que sin ser dueños de una mina les había sido asignada la explotación con la obligación de entregar parte de los productos o venderle los metales a un precio conveniente. Esto era trabajar "al pirquén".

Mario Bahamonde revela la vigencia del "pirquinear", como "andar realizando labores ocasionales y muy pobres, en general". ${ }^{139}$

Apuntemos que en la segunda mitad del siglo XIX, en las minas de Calama y alrededores, fue regular observar contratos que establecían que "el pirquén es libre desde la superficie hasta la cancha... (y) para posesionarse de un lote, se dará previo aviso al administrador, quien fijará la extensión que el pirquinero debe abarcar". ${ }^{140}$

Al margen de la ley pero sí enclavado en la tradición minera se apreció la acción de los "cangalleros", los que hurtaban minerales seleccionados por los mineros.

Esta costumbre, a juicio de Bahamonde, "los trabajadores se fundaban para hacerlo en que "el mineral lo da el cerro" y todo lo que forma parte del territorio es más o menos propiedad común del chileno". ${ }^{14}$

Las Ordenanzas aludían a "cateadores" o "buscones", sin precisar que eran las personas que realizaban la labor preliminar hacia el descubrimiento de una mina.

$Y$ en cuanto al personal más especializado distinguía los "peritos facultativos de minas" como los sujetos "intelijentes, instruidos i prácticos en la jeometría i en la arquitectura subterránea e hidráulica, i también en la maquinaria, i en las artes de carpintería, herrería i albañilería en la parte que se usa de ellas en el ejercicio de las minas" de los "peritos beneficiadores", aquellos "hombres hábiles en el conocimiento de los minerales, que llamen mineralojía, i en su tratamiento para sacarles todo lo que tuvieren de metales, i en el modo de reducir éstos al estado en que se hace uso de ellos así por mayor como por menor, que es lo que se llama metalurjia".

Las modificaciones introducidas en el lenguaje apuntaban en el siglo XVIII a ese ánimo de situar a las "ciencias útiles" como la palanca de progreso y reforma de las costumbres populares. ${ }^{142}$

\footnotetext{
${ }^{137}$ Antonio Dougnac, op. cit., p. 28.

${ }^{138}$ Vid. Mario Bahamonde, Diccionario de Voces del Norte de Chile, De, Nascimento, 1978.

${ }^{139}$ M. Bahamonde, op.cit., p. 288.

${ }^{140}$ Felipe Labastié, Estudio sobre el mineral de Caracoles, Antofagasta, 1907. 391.

${ }^{141}$ Mario Bahamonde, op. cit. p. 82. El escritor Carlos Pezoa Véliz, en su cuento fundacional de la literatura salitrera, "El taita de la Oficina", anota, significativamente, respecto de su personaje central: "El que sabía hacer una buena cangalla". Cf.Carlos Pezoa Véliz, "El taita de la Oficina" en Poesías y prosas completas, Ed, Nascimento, 1927.

${ }^{142}$ El cambio operado en la minería del siglo XVIII, no sólo se tradujo en la creación de nuevas instituciones-como la Real
} 
Lo expuesto puso de relieve el éxito relativo o no de aquella pretensión gubernamental en el área sociocultural,ante las inmemoriales costumbres de cómo laborar y designar el oficio en las capas del bajo pueblo.

El 16 de julio de 1874 el gobierno de Federico Errázuriz Zañartu exponía ante el Congreso Nacional los fundamentos del primer Código de Minería chileno. En la presentación del Proyecto hacía referencia a los cambios científicos operados en la explotación minera, los medios financieros y el incremento del número de industriales que "modifican incesantemente las condiciones de la minería, i reclaman cambios paralelos en la lejislación". ${ }^{143}$

El Código de Minería de 1874 mantenía algunos conceptos y locuciones. Las "calicatas", para referirse, en sus artículos 19 y 20, a las labores manores para descubrir metales. Determinadas denominaciones de las Ordenanzas de Nueva España eran asumidas en el Código.Así,por ejemplo, "socavón", "piques", "avíos", "desmontes", "escoriales", etc. La rica distinción minera quedaba contenida bajo las nociones de: "operarios" y "patrón".

A la engorrosa distinción de los "peritos" que esgrimía las Ordenanzas, se superponía un nuevo profesional, símbolo de la época de Progreso: el ingeniero de minas. ${ }^{144}$

Bajo el despliegue de la industria salitrera, principalmente en su fase del sistema Shanks, hasta 1929, se pudo contar con variados Reglamentos de Compañías Salitreras, en las provincias de Tarapacá y Antofagasta, que heredaron vocablos coloniales para referirse a determinados sitios del campamento-el más conocido fue "cancha"-, como para los oficios, donde el "apir", el "barretero" constituyeron los brazos más socorridos.

Al lenguaje castellano que asumía desde la vertiente indígena algunos préstamos lingüísticos, se sumó la introducción de anglicismos que denotaban claramente la preeminencia técnica y científica en que descansaba la industria salitrera.

Administración hasta sobrevenir el Tribunal de Mineria, en 1801, en Chile, sino el surgimiento de las "maritatas", como comunidades de pobres dedicadas a las faenas de relave.

Afirma A. Dougnac que en el siglo XVIII. Se acuño en México el oficio de "recogedores", llamados en Chile "Zeladores", los cuales, con licencia "de la justicia y de la diputación territorial, debian incitar a los ausentes a volver a sus tareas". cf. Antonio Dougnac, "Regulación de la Disciplina Laboral Minera en Chile Indiano". IX Congreso del Instituto Internacional de Historia, op. cit., Madrid, 1991, tomo I, 475.

La miseria de los trabajos mineros-de los "barreteros" o de los "apires"-denunciados por Manuel de Salas, contrasta con lo favorecido que había sido en sus comienzos. Cf. Sergio Villalobos R., "El bajo pueblo en el pensamiento de los precursores de 1810". Anales de la Universidad de Chile, N¹20, Cuarto trimestre de 1960.

${ }^{143}$ Proyecto de Código de Minería. Imp. de la República, Santiago, 1874, p. V.

${ }^{144}$ La Universidad de Chile, a partir de 1857, había comenzado a entregar los primeros títulos de ingenieros, de los que con especialidad como ingenieros de minas tuvieron en el Norte del país, desde Copiapó hacia el septentrión, incluido el desierto de Atacama, su campo de acción más eficaz. Cf. José Antonio González Pizarro, "Ideas y acciones del ingeniero de minas Matías Rojas Delgado:La minería y su relación con la Sociedad, Economía y el Derecho en el desierto de Atacama durante el siglo XIX", Vertiente. Revista de la Facultad de Ingeniería y Ciencias Geológicas, Universidad Católica del Norte, año 10, Nª. diciembre 1994, pp. 43-52. Una síntesis del cambio operado en el despoblado de Atacama, por el impacto de la ciencia y la técnica, se encuentra en José Antonio González Pizarro, "Ciencia y Minería en el desierto de Atacama en el siglo XIX Algunas observaciones", Vertiente. Revista de la Facultad de Ingenieria y Ciencias Geológicas, Universidad Católica del Norte, Año 9 , N9, 1993. 
Esta mezcla de "códigos privados" en las tareas mineras, para el salitre y para la cuprífera posteriormente, llamó la atención de diversos profesionales vinculados con la actividad minera. Citemos al ingeniero de minas Alejandro Bertrand que, de su experiencia en estas tórridas tierras, publicó en 1916 un Vocabulario Pampino. El abogado de la principal empresa salitrera, Aníbal Echeverría y Reyes, desde 1905 estudió el léxico salitrero, publicando dos importantes estudios. ${ }^{145}$

En aquellos registros, voces y expresiones como "Agua del tiempo". "A la vuelta", "Azuleado", "barrenador", "cachimba", "caldeado", "cascote", "coba", "colpa", "corrector", "costra", "chancar", "chuca", "ficha", "galleta", "libretera", "palla", "particular", referían a la emergencia de nuevas realidades sociales y económicas, donde la división del trabajo marcaba claramente la distinción entre los oficios sin instrucción-como el "particular"-de los especializados como también de los que discriminaban por grupos etários y sexo ${ }^{146}$, donde el "destazador" fue el niño operario que se ocupaba de ensanchar el fondo de los tiros para que contenga la cantidad necesaria de explosivos, ${ }^{147}$

Este nuevo acervo lingüístico que reconocía, como hemos indicado, anglicismos, como el "bogue", para referirse al armazón de fierro que sostiene las ruedas de los carros calicheros, proveniente del inglés "bogie", o bien "yajámber", "yajamen" del inglés "Jackhamer", etc. ${ }^{148}$, discurrió alejado de la producción jurídica, siendo heredado por los nuevos contingentes que, al rubricar su contrato de trabajo, se introducían en un ambiente cultural donde los lugares del campamento,los tratos diarios, las referencias a la tecnología, su propio hacer de oficio o profesión, iban asimilando un lenguaje fundacional para designar "cosas" o "situaciones" que para entonces desconocía. No siempre se tuvo conciencia de estar asistiendo a un hacer idiomático creativo, en su más plena acepción.

Las transformaciones de la técnica en la actividad salitrera no pudo alterar significativamente el léxico procedente de su primera forma de elaboración-las paradasy así, algunos vocablos pudieron adoptar acepciones particulares en la industria salitrera: "tarjetero", "bolón", "rancho": o bien constituyeron parte de la jerga salitrera, como "fino", "borra" "lágrima del salitre", etc. ${ }^{149}$

La explotación calichera aportó un tipo humano inédito: el "enganchador", personaje que se encargaba, con artimañas, reclutar trabajadores para las oficinas salitreras. Personaje real que simbolizó lo más odiado en los campamentos calicheros y fue "personaje" inesquivable en la literatura salitrera de la generación de 1938 o del $42 .{ }^{15}$

${ }^{145}$ Vid. Anibal Echeverria y Reyes, Vocablos Salitreros y Voces usadas en la Industria Salitrera, publicados en Antofagasta, en 1929.

${ }^{146}$ Una visión de conjunto, en José Antonio González Pizarro, "Los recursos humanos en la actividad salitrera. Una perspectiva histórica", Contingencias, Facultad de Economía, Universidad Católica del Norte, Antofagasta, mayo de 1996.

${ }^{147}$ Véase, el léxico presentado por Sergio González Miranda, Glosario de Voces de la Pampa. Tarapacá en el Cíclo del Salitre, Taller de Estudios Regionales, Iquique, 1993.

${ }^{148}$ Cf. Roberto Lehnert Santander, "Anglicismos en el léxico salitrero". Cuadernos de Filología, Universidad de Chile, Sede Antofagasta, $1976, \mathrm{~N}^{\circ} 4$.

${ }^{149} \mathrm{Cf}$. el estudio realizado por Angel Araya Peña et.al., Muestra cartográfica y glosario del léxico del salitre. Universidad del Norte, Antofagasta, Alenoch (Atlas Lingüístico del Norte de Chile), II Región, 1982.

${ }^{150}$ A modo de ejemplo, Andrés Sabella ofreció un retrato sugestivo del "enganchador", en su novela Norte Grande: 
Un prototipo social distante de las leyes pero eficaz para modificar la fisonomía humana del desierto.

En el ámbito minero cuprero aconteció un fenómeno similar pero con matices en sus comienzos.Aun cuando se tienen antecedentes de la explotación de cobre en tiempos prehispánicos, sólo en este siglo la región de Antofagasta vio incorporarse la industria cuprífera con parecida incidencia en el erario público, con una gravitación en lo socio-económico,desde 1915 cuando empezó la Chile Exploration Co.,a laborar el mineral de Chuquicamata-"dura lanza" en lengua kunza-hasta desplegarse una actividad que engloba la pequeña minería, representada por lo pirquineros de Tocopilla, y una mediana minería en Mantos Blancos o en Carolina de Michilla.

En este sentido, las voces de esta actividad, asumen en determinados oficios la heredada desde la salitrera, pero esencialmente consigna anglicismos por la misma introducción técnica, maquinarias y herramientas.

En su registro, algunas voces delatan su procedencia desde la industria salitrera, adoptando otras sinonimias, como por ejemplo, "Cachorrero" que designaba al obrero pampino cuya labor consistía en reducir los bolones de caliche más grandes ${ }^{151}$. En la faena cuprera pervivía pero acompañada de "barretero", "perforo", "perforista", "cargador de tiro", "cargador", "barrenador", "burrero" ${ }^{152}$.

Sin embargo, el "pirquinero" en la actividad cuprera también se le llamaba "cabeza de cuadrilla", "particular", "pallaco", "pallaquero", verificándose en "particular" el prototipo del minero calichero, como operario pagado por tarea, y en el "pallaquero" una voz de mucho arraigo, pues se le consignaba desde fines del siglo XVIII, para nombrar al que apartaba y escogía las porciones metálicas mineralizadas.

De esta manera, los días de trabajo minero de siglos no sólo significaron faenas productivas sino acciones culturales, a través de la nominación de tareas para distintos oficios que se empleaban en los variados procedimientos mineros en la Colonia y en las décadas republicanas. Aquello fue comprendido por los peritos en Leyes para normar las actividades con voces técnicas y usuales en la época.

La estructuración de una normativa única, en el ambiente del proceso de codificación jurídica nacional, que se vivió desde mediados del siglo XIX en nuestro país, fue haciendo más "abstracta" la referencia a esta riqueza designativa de las ordenanzas hispanoamericanas coloniales. Lo que se perdió en la relación con lo consuetudinario de los oficios, lo precisó con el rigor exigido por los avances técnicos y científicos de los propios profesionales relacionados con la actividad minera.

Sin embargo, en la estructura misma de las actividades mineras se forjaron y/o recrearon los códigos privados de las peculiaridades no sólo humanas sino de sus propios ciclos productivos. Allí pervivió -y pervive- la simiente cultural más real de las faenas mineras.

\footnotetext{
"Las Compañias les proporcionaban bastante dinero, la llave para abrir el arca de las tentaciones. El "enganchador" partía bizarro, como un rey: el sombrero ladeado de los conquistadores; el diente de oro, una lámpara y un argumento; una chalina en el cuello grueso, de toro colorado; el traje de casimir inglés; y la cadena de oro con la libra esterlina, como un ojo que no miente. Los zapatos brillaban; y el reloj reía presto para anunciarle más tiempo a las fiestas"

${ }^{151}$ Mario Bahamonde,op.cit.p.71.

${ }^{152}$ Cf. Angel Araya Peña et. al, Muestra cartográfica léxico del cobre. Universidad del Norte, Antofagasta, Alenoch (Atlas Lingüístico del Norte de Chile), II Región, 1985.
} 